\title{
Psychiatric Morbidity Patterns in Referred Inpatients of Other Specialties
}

\author{
Ajay Risal,' Pushpa Prasad Sharma' \\ 'Department of Psychiatry, Dhulikhel Hospital, Kathmandu University School of Medical Sciences (KUSMS), Dhulikhel, Kavre, \\ Nepal.
}

Introduction: Consultation-liaison psychiatry is an upcoming field dealing with interdepartmental collaboration heading into multidisciplinary and holistic care. In general hospital setting, psychiatrists need to be involved in evaluation of patients referred from other specialties. This study analyzed the psychiatric morbidity among the inpatients referred to Psychiatry Department from different wards in a Tertiary care University Teaching Hospital.

Methods: Total 385 subjects were referred to the Department of Psychiatry from different wards during a period of one year. Each of them underwent a detailed psychiatric evaluation by a consultant psychiatrist once they were medically stable. Psychiatric diagnosis was considered as per International Classification of Disease-10 criteria.

Results: The mean age of the subjects evaluated was $37.26( \pm 1.86)$; most of them were females 216 (56.4\%), married 287 (74.5\%), and homemaker 159 (41.3\%). Maximum 271 (70.4\%) referral was from Medical ward, and most of them $292(75.8 \%)$ were admitted in general bed. The most common medical diagnosis was self-poisoning 115 (30.6\%) followed by alcoholic liver disease 49 (12.7\%); while the commonest 123 (31.9\%) psychiatric diagnosis was depression (including Dysthymia and Adjustment disorder). Depression remained the commonest diagnosis among those referred from medical ward 131 (34.7\%); while anxiety was mostly found in the emergency referral $94(24.5 \%)$. Significant Correlation $(\mathrm{P}<0.05)$ was seen between the source of referral and Psychiatric diagnosis.

Conclusions: Psychiatric consultation was sought mostly by medical ward that had maximum number of patients presenting with self-poisoning. The commonest diagnosis seen in the referred in-patients was depression and anxiety disorder.

Keywords: consultation-liaison psychiatry; in-patient referral; psychiatric morbidity.

\section{INTRODUCTION}

All illnesses are considered to have both psychological and physical dimensions. ${ }^{1}$ Association between physical illness and psychiatric morbidity has been well recognized and evidenced in different studies. ${ }^{2-7}$

Consultation-Liaison Psychiatry has been considered to be an interface between Psychiatric and Non-psychiatric medicines as practiced in general hospital setting. ${ }^{8-10}$
Though it has been shown that the organization of consultation service and its efficiency are factors interfering with the rates of referral, studies looking into psychiatric referral patterns in different hospital settings

Correspondence: Dr. Ajay Risal, Dhulikhel Hospital, Kathmandu University School of Medical Sciences, P.O. BOX No. 11008, Kathmandu, Dhulikhel, Kavre, Nepal. Email: drajayrisal@gmail.com, Phone: 9849550155 . 
do not show comparable results. ${ }^{11-16}$ Similarly, literature looking into the factors leading to the lower referral rates in Psychiatry is sparse and inconclusive. ${ }^{17-24}$

Keeping this in mind, this study was undertaken in a University Teaching Hospital setting with the aim to evaluate the patterns of referral of inpatients from other specialties to the Department of Psychiatry and describe the apparent psychiatric morbidity patterns of those patients.

\section{METHODS}

This descriptive cross-sectional study was conducted in the Department of Psychiatry, Dhulikhel Hospital (Kathmandu University Hospital) after getting approval from the Institutional Review Committee (IRC) of Kathmandu University School of Medical Sciences (KUSMS). The study population included all those patients admitted in different wards of Dhulikhel Hospital from $1^{\text {st }}$ October 2010 to $30^{\text {th }}$ September and referred for psychiatric evaluation to the Department of Psychiatry. Each patient underwent a detailed psychiatric evaluation by a consultant psychiatrist once they were medically stable. Psychiatric diagnoses were considered as per ICD-10 criteria. ${ }^{25}$ Details of the patients including socio-demographic data, medical/ surgical diagnosis, psychiatric diagnosis and outcome were studied.

There were total 385 subjects referred from different wards (including Emergency and ICU) for Psychiatric evaluation during the study period of one year. All of them were evaluated in detail once they were clinically stable. Socio-demographic details of subjects, month of evaluation, source of referral, place of admission, medical/ surgical and psychiatric diagnosis and psychiatric management done were tabulated and analyzed. SPSS software package (Version 16, SPSS Inc., Chicago, USA) was used to analyze the data. Descriptive statistics and correlation coefficient was used to obtain the desired results.

\section{RESULTS}

The maximum number of the subjects was found to be in the age group 11-40 years; mean and median age was $37.26( \pm 1.86)$ and 35.5 respectively. There was female predominance; female: male ratio was 1.29:1. Almost three-fourth of the study population was married; one-quarter belonged to Brahmin caste and maximum were homemaker and agriculturist by occupation (Table 1). Frequency of referral was the highest in the months March to May, and again in September. Referral rate was calculated to be $385(3.78 \%)$ (Table 2).

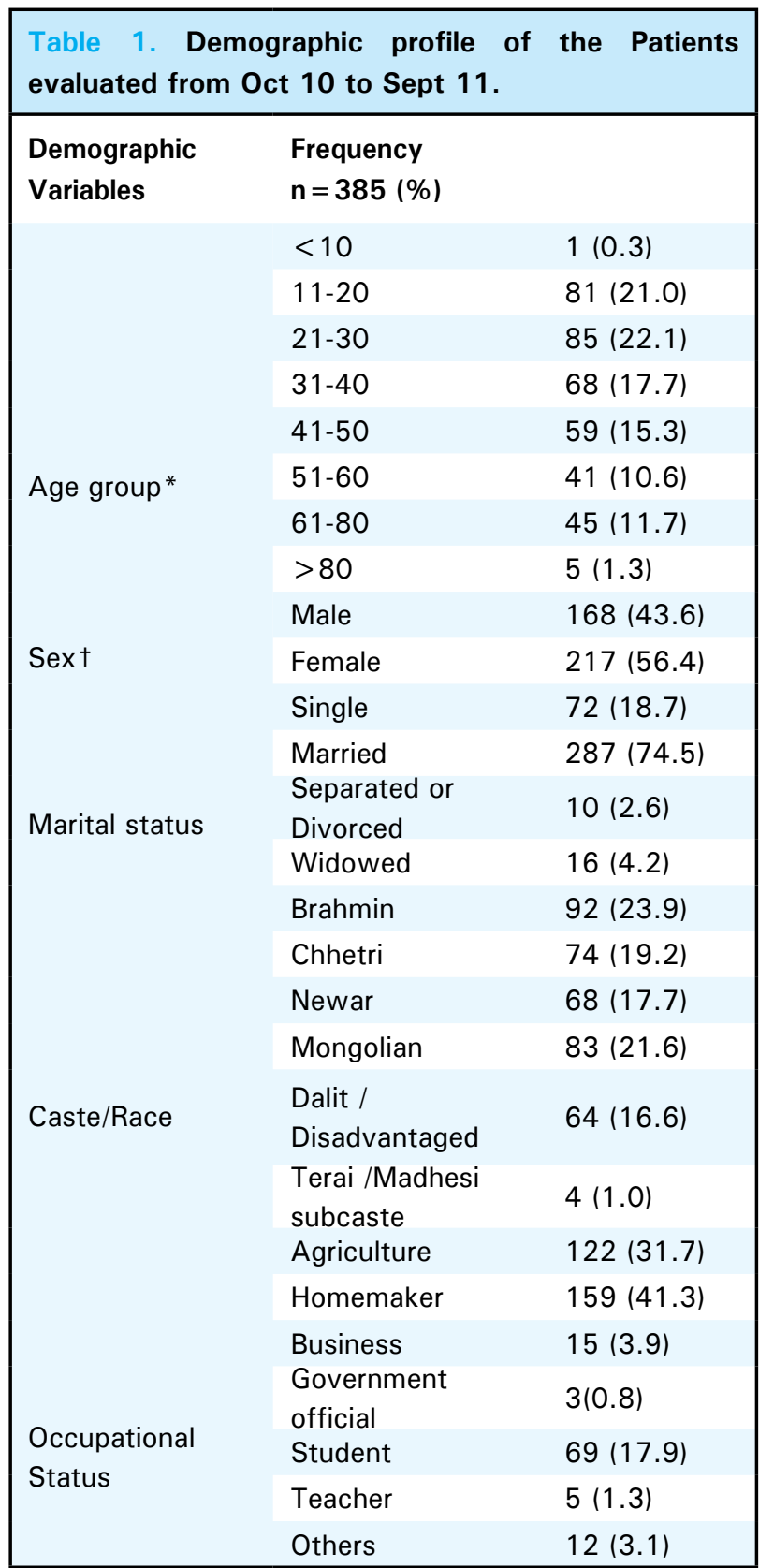

*Mean ( \pm Standard Deviation) =37.26 ( \pm 1.86$)$; Median Age $=35.5 ; \dagger$ Female: Male ratio $=1.29: 1$

The Medical ward referred 271 (70.4\%) while the referral from Emergency was 53 (almost 14\%). Three-quarters of the patients were admitted in the general ward (Table 3). The commonest medical diagnosis among the referred in-patients was selfpoisoning 115 (30.6\%); alcoholic liver disease was also common 46 (12.7\%). However, 46 (12\%) were found to have no medical/surgical diagnosis (Table 4).

Psychiatric evaluation was done once the referred patients were medically stable and the diagnosis was considered as per the ICD-10 criteria. ${ }^{25}$ Almost one- 
Ajay et al. Psychiatric Morbidity Patterns in Referred Inpatients of Other Specialties

third of the subjects were found to have depressive illness (including Dysthymia and Adjustment Disorder); a quarter of them had Alcohol related psychiatric problem (dependence/ withdrawal). Other common Psychiatric disorders were Personality disorder, Anxiety disorder, and Dissociative disorder. However, in 34 (around 9\%) were found to have no Psychiatric illness of any kind while in 11 (around 3\%), psychiatric diagnosis could not be made as they could not be evaluated further (Table 5).

It was seen that among the total 271 patients referred from Medical ward, the commonest diagnosis was depressive illness 95 (35\%); followed by alcohol withdrawal $76(28 \%)$ and personality disorder 45 $(16.6 \%)$. While among the Emergency referral cases (53), the common psychiatric diagnosis were Anxiety disorder 65 (24.5\%), alcohol withdrawal 35 (13.2\%) and dissociative disorder $30(11.3 \%)$. Similarly, among the 93 patients admitted in ICU setting, Psychiatric evaluation following clinical stabilization revealed Depressive Illness $37(40 \%)$ to be the commonest psychiatric problem followed by personality disorder 28 (30\%) (Table 6).

\begin{tabular}{|lll|}
\hline $\begin{array}{l}\text { Table 2. Month } \\
\text { Patients. }\end{array}$ & wise Presentation of Referred \\
\hline $\begin{array}{l}\text { Month of } \\
\text { evaluation }\end{array}$ & $\begin{array}{l}\text { Total In- } \\
\text { Patients }\end{array}$ & $\begin{array}{l}\text { Frequency of } \\
\text { referred patients } \\
\text { n (\%) }\end{array}$ \\
October 2010 & 814 & $27(3.32)$ \\
November 2010 & 763 & $15(1.96)$ \\
December 2010 & 908 & $23(2.53)$ \\
January 2011 & 777 & $28(3.6)$ \\
February 2011 & 780 & $26(3.33)$ \\
March 2011 & 855 & $40(4.67)$ \\
April 2011 & 816 & $48(5.88)$ \\
May 2011 & 853 & $43(5.04)$ \\
June 2011 & 904 & $37(4.09)$ \\
July 2011 & 829 & $28(3.38)$ \\
August 2011 & 940 & $27(2.87)$ \\
September 2011 & 930 & $43(4.62)$ \\
Total & 10169 & $385(3.78)$ \\
Referral Rate $=3.78 \%$ & \\
\hline
\end{tabular}

\begin{tabular}{|ll|}
\hline Table 4. Medical/ Surgical Diagnosis of the Patients \\
evaluated. & $\mathbf{n}(\%)$ \\
\hline Medical/ Surgical Diagnosis & $4(1.0)$ \\
Abortion & $49(12.7)$ \\
Alcoholic Liver Disease & $22(5.7)$ \\
APD & $4(1.0)$ \\
Catatonia & $22(5.7)$ \\
COPD & $26(6.8)$ \\
Delirium & $5(1.3)$ \\
Diabetes Mellitus & $2(0.5)$ \\
Hanging & $8(2.1)$ \\
Headache Syndrome & $11(2.9)$ \\
PID & $118(30.6)$ \\
Poisoning & $10(2.6)$ \\
Post-operative status & $4(1.0)$ \\
Postpartum state & $3(0.8)$ \\
RTA & $11(2.9)$ \\
Seizure Disorder & $47(12.2)$ \\
Nil & $39(10.1)$ \\
Others &
\end{tabular}

\begin{tabular}{|c|c|}
\hline Psychiatric Diagnosis & $\begin{array}{l}\text { Frequency } \\
(n=385)(\%)\end{array}$ \\
\hline Organic mental illnesses/Delirium & $15(3.9)$ \\
\hline $\begin{array}{l}\text { Alcohol Dependence syndrome/ } \\
\text { withdrawal }\end{array}$ & $89(23.1)$ \\
\hline $\begin{array}{l}\text { Psychosis / Schizophrenia } \\
\text { spectrum disorder }\end{array}$ & $15(3.9)$ \\
\hline $\begin{array}{l}\text { Depression/ Dysthymia / } \\
\text { Adjustment Disorder }\end{array}$ & $123(31.9)$ \\
\hline Mania/Bipolar Disorder & $3(0.8)$ \\
\hline Anxiety spectrum disorder & $21(5.5)$ \\
\hline $\begin{array}{l}\text { Childhood psychiatric illnesses/ } \\
\text { Mental Retardation }\end{array}$ & $1(0.3)$ \\
\hline Dissociative disorder & $18(4.7)$ \\
\hline Personality disorder & $49(12.7)$ \\
\hline Others & $6(1.6)$ \\
\hline No psychiatric diagnosis made & $34(8.8)$ \\
\hline Further evaluation required & $11(2.9)$ \\
\hline
\end{tabular}


Table 3. Referral patterns of the patients.

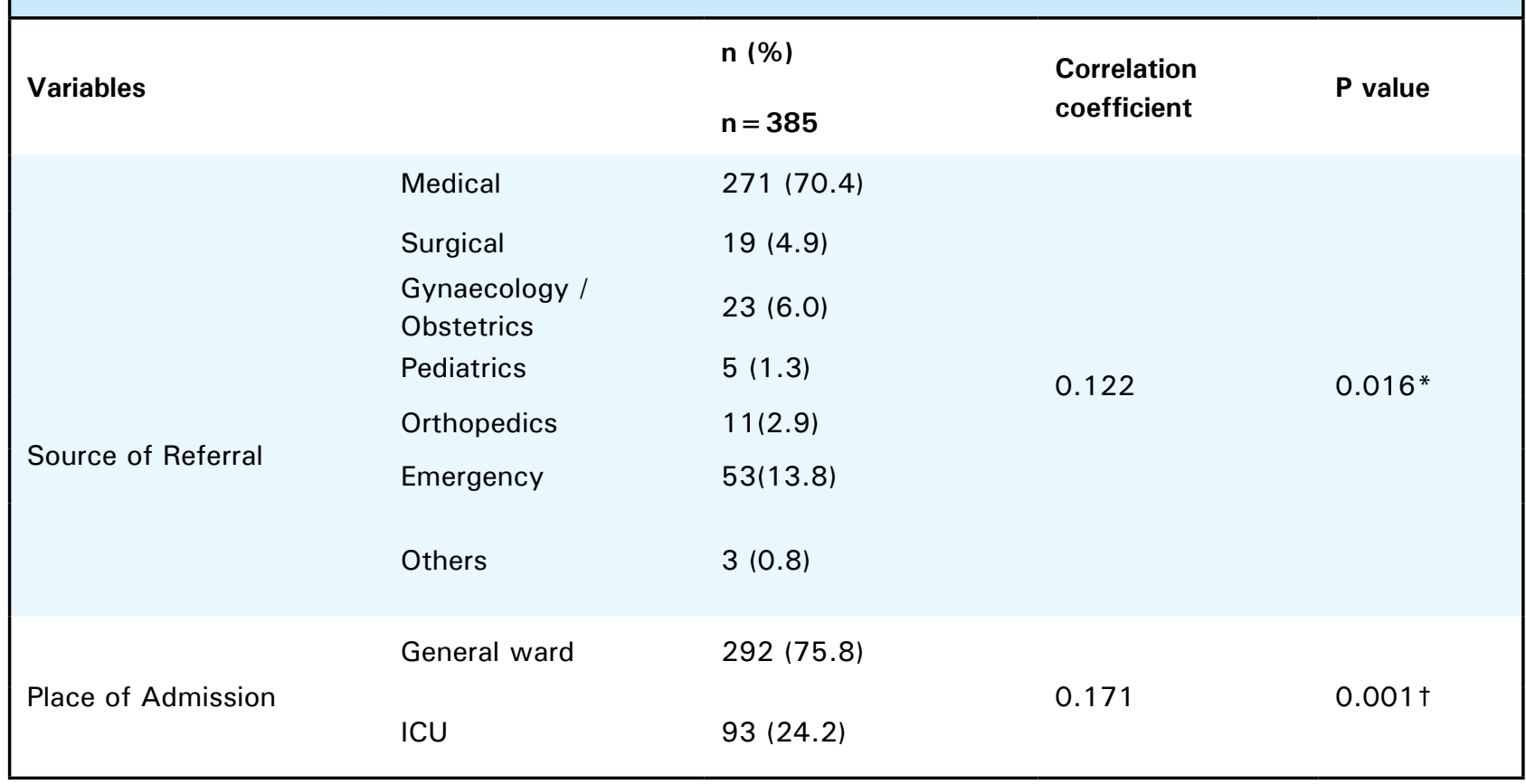

${ }^{*} P<0.05,+P<0.01$.

Table 6. Psychiatric Diagnosis among the Patients referred from Medical ward and Emergency and those admitted in ICU.

\begin{tabular}{|c|c|c|c|}
\hline Psychiatric Diagnoses & $\begin{array}{l}\text { Referral from Medical } \\
\text { ward } \\
(n=271)(\%)\end{array}$ & $\begin{array}{l}\text { Referral from } \\
\text { Emergency } \\
(n=53)(\%)\end{array}$ & $\begin{array}{l}\text { Admitted in ICU } \\
(n=93)(\%)\end{array}$ \\
\hline Organic mental illnesses/ Delirium & $8(3.0)$ & $2(3.8)$ & $2(2.2)$ \\
\hline Alcohol withdrawal & $76(28.0)$ & $7(13.2)$ & $14(15.1)$ \\
\hline Psychosis spectrum disorder & $8(3.0)$ & $2(3.8)$ & $3(3.2)$ \\
\hline $\begin{array}{l}\text { Depression, Dysthymia and Adjustment } \\
\text { disorder }\end{array}$ & $94(34.7)$ & $6(11.3)$ & $36(38.7)$ \\
\hline Mania /Bipolar Disorder & $2(0.7)$ & $1(1.9)$ & NA \\
\hline Anxiety spectrum disorder & $5(1.8)$ & $13(24.5)$ & NA \\
\hline Dissociative disorder & $10(3.7)$ & $6(11.3)$ & $4(4.3)$ \\
\hline Personality disorder & $45(16.6)$ & $3(5.7)$ & $27(29.0)$ \\
\hline Others & $1(0.4)$ & $3(5.7)$ & NA \\
\hline Further evaluation required & $7(2.6)$ & $2(3.8)$ & $2(2.2)$ \\
\hline No Psychiatric diagnosis made & $15(5.5)$ & $8(15.1)$ & $5(5.4)$ \\
\hline
\end{tabular}




\section{DISCUSSION}

The emergence of the concept of Consultation-Liaison Psychiatry half a decade back brought a new momentum in the health care management system as it was considered to be a mechanism which bridges the gap between psychiatry and general medicine providing a clear picture of the disorders occurring in hospital practice..$^{1,2}$ Its significance was considered in terms of holistic care approach that looks upon both the psychological and physical components of any illness; moreover leading to a comprehensive physical and psychological care, shorter in-patients stay, better quality of life, less distress and decreased rate of deliberate self harm. ${ }^{1}$

The importance of such practices cannot be overestimated in General Hospital settings in general; and University Teaching Hospital like ours in particular. Though there is regular Psychiatric service in any Medical College Teaching Hospital in our country and most of the other General Hospitals, the referral rates from other departments for psychiatric consultation varies. ${ }^{17,18}$ Even the studies done in India, other South American and African regions show differences in referral rates in comparison to some other Western studies. ${ }^{12-16}$

Keeping these facts in mind, we intended to conduct a study in our Teaching Hospital setting; to explore the referral patterns from other Departments to our Department of Psychiatry in order to initiate an attempt to understand the factors affecting the practices of Consultation-Liaison Psychiatry in our centre. In the study period of one year, we evaluated medical/ surgical and psychiatric diagnosis (if any) of the patients referred for psychiatric evaluation from other different wards in our hospital and tried to analyze the interrelationship between them and their primary source of referral; in addition to the descriptive analysis of the socio-demographic profile and treatment related factors of those subjects.

Referral rate for Psychiatric evaluation in our study was $3.78 \%$ which was comparable to a similar study done in a General Hospital setting at Bangalore. ${ }^{16}$ However other Indian studies have shown lower referral rates. ${ }^{14,15,26}$ In a study done in a medical college setting in Kathmandu, referral rate was $1.4 \% .{ }^{17}$ Similar is the case in Brazil and South Africa, where psychiatric referral has been found to be less in comparison to that in Western Hospitals. ${ }^{12,13}$ Psychiatric referral rate in our centre can be considered somewhat encouraging keeping in mind the facts we received from the earlier studies done elsewhere. Referral rates in the summer months (March to May) was maximum in comparison to the other months of the year which can be attributed to the fact that self-poisoning which is the most common medical diagnosis $(30.6 \%)$ among these patients is also higher in these months leading to increase in the Psychiatric referral load; it corroborates with the findings in our study done last year in the same centre looking into the psychiatric profile of the patients presenting with Intentional self harm. ${ }^{27}$

The study revealed that the maximum numbers of subjects were in their second to the fourth decades of life, females, homemakers and married; keeping with the findings from earlier similar studies done elsewhere and that of the study done last year in the

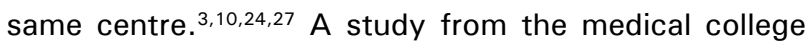
setting in Eastern Nepal however showed slightly more predominance of males and teenagers. ${ }^{18}$ Almost three quarters of our patient sample were referred from the Medical ward, one-tenth were from the Emergency Department; which is in keeping with the findings from a British case-record study. ${ }^{10}$ Almost half of the referrals were from Medicine Department in the Kathmandu based Medical College study. ${ }^{17}$ Similarly, in the study of Eastern Nepal, referral from medicine and Emergency Department made almost one-third of the total patient sample. ${ }^{18} \mathrm{~A}$ recent research conducted in India looking into the psychiatric referral patterns also revealed more than $50 \%$ referrals were from General Medicine. ${ }^{9}$ Maximum referral from physicians in our study is probably related to high number of cases with self poisoning as quoted in earlier studies. . $^{3,10,16,27}$ When self-poisoning cases were excluded, maximum referrals were found for alcohol related problems, mostly withdrawal symptoms $(12.7 \%)$ and delirium $(6.8 \%)$; as has been shown in other studies. ${ }^{1,12,16}$

Detailed psychiatric evaluation of these referred inpatients revealed commonest diagnosis to be depression $(32 \%)$, followed by Alcohol Dependence Syndrome $(23 \%)$ and personality disorder (13\%). Mostly the personality disorders were of Emotionally Unstable (Impulsive) or Mixed type as per the ICD-10 criteria, though we had not used any scale for Personality Disorder Identification. Most of them were admitted for Intentional Self Harm (ISH), some had multiple attempts, hence impulsive traits/ personalities were seen commonly. Other similar studies done at various centers in India and abroad also showed Depression to be the most common psychiatric diagnosis in referred patients. ${ }^{3,10,16,24,28}$ Depression was common even in the Kathmandu study. ${ }^{17}$ In Dharan, Dissociative disorders were more prevalent among the referred patients. ${ }^{18}$ The least diagnosed conditions were Psychosis $(3.9 \%)$ and Mania $(0.8 \%)$ as in an Indian study. ${ }^{16}$ In contrast to findings from some other studies, there were less referral from Gynecology and Obstetrics $(6 \%)$, Surgery $(4.9 \%)$ and Orthopedics (2.9\%). ${ }^{22,29}$

Almost a quarter of the patients referred from Emergency were later diagnosed to have Anxiety spectrum disorder (mostly panic); followed by Alcohol withdrawal (13.2\%) 
and Dissociative disorder (11.3\%). Most of these patients were brought to the Emergency with history of suicidal attempt, excitement, violence and altered sensorium as seen in a similar study of emergency psychiatric referrals in a teaching general hospital in India. ${ }^{30}$

Psychiatric evaluation of the patients admitted in ICU setting once they were medically stable revealed maximum (39\%) of them had depression followed by personality disorder (29\%) showing a statistically significant correlation, as seen in a recent Indian study. ${ }^{1}$

More than one-tenth of the referred patients in our study had no physical diagnosis, which can be considered to be psychologically determined; hence related to the large load of Depression and Anxiety Disorder as discussed in some earlier studies and a recent South African study. ${ }^{13,16,31}$ A community study of Psychiatric illnesses in the patients coming for treatment in a Health camp conducted in Eastern Nepal also demonstrated the load of Depression and Anxiety; in keeping with the findings of this Hospitalbased study. ${ }^{32}$ Even in Western Nepal, a recent study looking for the load of psychiatric illnesses in the OPD patients in a private hospital showed predominance of Neurotic illnesses and Mood Disorders comprising above $50 \%$ of the total patients evaluated. ${ }^{33}$

In around $9 \%$ of the cases, no psychiatric diagnosis could be made; either they could not satisfy the ICD-10 criteria for any psychiatric disorder or we could not get sufficient time to evaluate them in detail due to early discharge.

In summary, our study attempted to explore the possibility of the presence of psychological factors playing their role in the variety of physical illnesses among the patients admitted in different wards of a tertiary level
Teaching Hospital; hence illustrating the importance of psychiatric evaluation of medical/ surgical cases and significance of an emerging field in the Mental Health care delivery system, i.e. Consultation-Liaison Psychiatry.

However, this study had certain limitations as well; our study cohort included only the hospitalized patients referred for psychiatric evaluation posing difficulty in the generalization of the results as selection bias might have been a limiting factor in this case. Different outcomes may be expected in out-patient or community setting.

\section{CONCLUSIONS}

Psychiatric consultation was sought mostly by medical ward with a maximum number of patients presenting with self-poisoning and the commonest psychiatric diagnosis seen in the referred in-patients was depression and anxiety disorder. Our study basically highlighted the importance of an increase in the awareness of the presence of psychological factors in physical illnesses leading to holistic care of an individual patient; which can be achieved in a general hospital setting through Consultation-Liaison psychiatry.

\section{ACKNOWLEDGEMENTS}

We would like to thank Mr. Seshananda Sanjel, MPH, Lecturer, Department of Community Medicine, KUSMS, Dhulikhel, Kavre, Nepal for his assistance in statistical analysis and Dr. Ramesh Makaju, MD, Associate Professor, Department of Pathology, Dhulikhel Hospital, KUSMS, Dhulikhel for helping in the preparation of manuscript.

\section{REFERENCES}

1. Mahar MR, Jehangir S, Khan FH, Arain T, Jalil $S$, Karim F. Frequency of psychiatric disorders in referred hospitalized patients of other medical disciplines a hospital based study. PAFMC[serial online] 2010[cited 2012 Feb 1];3. Available from: URL http://www.pafmj.org

2. Lloyd OG. Psychological reactions to physical illness. British Journal of Hospital Medicine. 1977;18:352-8.

3. Doongaji DR, Nadkarni RP, Bhatawdekar ML. Psychiatric referrals in two general hospitals. J Postgrad Med[serial online] 1989 [cited 2012 feb 1];35:171. Available from: URL:http://www. jpgmonline.com/text.asp?1989/35/3/171/5694
4. Alhuthail YR. Psychiatric consultations and length of hospital stay. Neurosciences. 2008;13(2):161-4.

5. Grover S. State of consultation-liaison psychiatry in India: Current status and vision for future. Indian J Psychiatry. 2011;53(3):202-13.

6. Lipowski ZJ. Psychosomatic medicine in the seventies: an overview. American Journal of Psychiatry. 1977;134:233-44.

7. Lipowski ZJ. Current trends in consultation-liaison psychiatry. Can J Psychiatry. 1983;28:329-38.

8. Barczak P. Liaison Psychiatry. Bulletin of the royal college of psychiatrists. 1986;10:178-80. 
9. Parkar SR, Sawant NS. Liaison psychiatry and Indian research. Indian J Psychiatry. 2010;52(7):386-8.

10. Brown A, Cooper AF. The impact of a liaison psychiatry service on patterns of referral in a general hospital. British Journal of Psychiatry. 1987;150:83-7.

11. Seward LM, Smith GC, Stuart GW. Concordance with recommendation in a consultation-liaison psychiatry service. Aust N Z J Psychiatry. $1991 ; 25: 243-54$.

12. Smaira SI, Correa FK, Contel JO. Psychiatric disorders and psychiatric consultation in a general hospital: a case- control study. Rev Bras Psiquiatr. 2003;25(1):18-25.

13. Govender RC, Oosthuizen P, Cloete KJ. Diagnostic outcome of patients referred to psychiatry with medically unexplained symptoms: a retrospective study. Afr J Psychiatry. 2011;14:45-9.

14. Jindal RC, Hemrajani DK. A study of psychiatric referrals in a general hospital. Indian $J$ Psychiatry.1980;22:108-10.

15. Prabhakaran M. Inpatient psychiatric referrals in a general hospital. Indian J Psychiatry. 1968;10:73-5.

16. Srinivasan K, Babu RK, Appaya P, Subrahmanyam HS. A study of inpatient referral patterns to a general hospital psychiatry unit in India. General Hospital Psychiatry. 1987;9(5):372-5.

17. Singh PM, Vaidya L, Shrestha DM, Tajhya R, Shakya S. Consultation liaison psychiatry at Nepal Medical College and Teaching Hospital. Nepal Med Coll J. 2009;11(4):272-4.

18. Shyangwa PM, Joshi D, Sherchan S, Thapa KB. Psychiatric morbidity among physically ill persons in eastern Nepal. Nepal Med Coll J. 2009;11(2):118-22.

19. Mayou R, Hawton K. Psychiatric disorder in the general hospital. Br J Psychiatry. 1986;149:172-90.

20. Seltzer A. Prevalence, detection and referral of psychiatric morbidity in general medical patients. J Roy Soc Med. 1989;82:410-2.

21. Steinberg $H$, Toren M, Saravay SM. An analysis of physician resistance to psychiatric consultation. Arch Gen Psychiatry. 1980;37:1007-12.
22. Schwab JJ, Clemmons RS, Freemon FR, Scott ML. Differential characteristics of medical in-patients referred for psychiatric consultation: a controlled study. Psychosomatic Medicine. 1945;27(2):112-8.

23. Bustamante JP, Ford CV. Characteristics of general hospital patients referred for psychiatric consultation. J Clin Psychiatry. 1981;42:338-44.

24. Lipowski ZJ, Wolston EJ. Liaison psychiatry: referral patterns and their stability over time. American Journal of Psychiatry. 1981;138:1608-11.

25. The ICD-10 classification of mental and behavioral disorders-clinical descriptions and diagnostic guidelines. Geneva: WHO; 1992.

26. Parekh HC, Desmukh BD, Bagadia VN, Vahia NS. Analysis of indoor psychiatric referrals in a general hospital. Indian J Psychiatry. 1968;10:81-3.

27. Risal A, Sharma PP. Psychiatric manifestations of patients admitted for intentional self harm. Journal of Institute of Medicine. 2011;33(1):43-8.

28. Rosen DH, McMillan F, Gregory RJ, Pollock D, Schiffmann A. Depression in patients referred for psychiatric consultation: a need for a new diagnosis. General Hospital Psychiatry. 1987;9(6):391-7.

29. Agrawal P, Malik SC, Padubidri SC. A study of psychiatric morbidity in gynecology out patient clinic. Indian J Psychiatry. 1990;32(1):57-63.

30. Kelkar DK, Chaturvedi SK, Malhotra S. A study of emergency psychiatric referrals in a teaching general hospital. Indian J Psychiatry. 1982;24:366-9.

31. Kaufman M. A psychiatric evaluation of the problem patient. JAMA. 1957;16:108-10.

32. Shakya DR. Psychiatric morbidity pattern in a health camp in Eastern Nepal. Health Renaissance. 2010;8(3):186-91.

33. Khattri JB, Godar ST, Thapa P, Ramesh K, Chakrabortty PK, Thapa BB. Socio-demographic characteristics and diagnostic profile of patients attending psychiatric OPD of a private hospital in western region of Nepal. Nepal Journal of Medical Sciences. $2012 ; 1(1): 15-8$. 